\title{
Synthesis of a photocrosslinkable hyperbranched polyester containing methacryloyl groups by the reaction of 1,4-bis(chloromethyl)benzene with 1,3,5-benzenetricarboxylic acid followed by reaction with methacrylic acid
}

\author{
Ken Maruyama, Toshiaki Hirabayashi, Hiroto Kudo and Tadatomi Nishikubo \\ The synthesis and photo-polymerization of hyperbranched polyesters (HBPEs) containing terminal methacryloyl groups \\ (HBPE-MA) were examined. Polycondensations of 1,4-bis(chloromethyl)benzene with 1,3,5-benzenetricarboxylic acid using 1, \\ 8-diazabicyclo[5.4.0]undec-7-ene as a base were performed to give the soluble HBPEs in satisfactorily high yields. Furthermore, \\ HBPE-MA was synthesized by the reaction of HBPE with methacrylic acid. The photo-induced radical polymerization of \\ HBPE-MA was performed in the presence of 2-methyl-1-[4-(methylthio)phenyl]-2-morpholinopropan-2-one (Irgacure 907), \\ which acts as a photoinitiator in the solid film state and yields an insoluble cured film upon ultraviolet irradiation. \\ Polymer Journal (2010) 42, 790-794; doi:10.1038/pj.2010.74
}

Keywords: DBU; hyperbranched polymer; photoradical polymerization; polyester

\section{INTRODUCTION}

Radiation-curing technology has been widely used in many applications such as adhesives, aerospace, electronics, printing, auto refinishing and ultraviolet (UV) inkjets. ${ }^{1-3}$ These technologies, which are based on radical reactions using (meth)acrylated monomers and oligomers such as (meth)acrylated epoxy resin, polyurethane and polyester, are mainly used due to their high performance. Recently, research on the new applications of radiation-curing technology has also been reported. Shirai et al. ${ }^{4}$ reported on a negative-tone photo-resist for extreme UV lithography based on radical reactions using multifunctional thiol compounds and poly(4-hydroxystyrene) containing $\mathrm{C}=\mathrm{C}$ double bonds such as (meth)acryloyl groups.

Alternately, hyperbranched polymers (HBPs) attract attention due to their unique properties such as lower viscosity, ${ }^{5,6}$ good solubility ${ }^{7}$ and a large number of terminal functional groups compared with the corresponding linear ones. HBPs can be synthesized by two methods: one is the self-polymerization of $\mathrm{AB}_{2}$-type monomers; ${ }^{8-10}$ the other is the copolymerization of an $\mathrm{A}_{2}$-type monomer with a $\mathrm{B}_{3}$-type monomer. ${ }^{11,12}$ The latter has a significant advantage for industrial applications because commercially available monomers can be used as the starting materials.

There have been many reports on the synthesis and characterization of HBPs. Ueda et al. ${ }^{13}$ reported on the synthesis of a HBP, with an approximately $100 \%$ degree of branching, by the polycondensation of 2-(4-phenoxyphenoxy)fluorenone. We examined ${ }^{14-16}$ the synthesis of hyperbranched polyester (HBPE) epoxy resins containing methacryloyl groups (HBPE(ep)-MA), hyperbranched oxetane resin containing methacryloyl groups (HBPE(ox)-MA) and hyperbranched polyurethane containing methacryloyl groups (HBPU-MA) by the reaction of an $\mathrm{A}_{2}$-type monomer with a $\mathrm{B}_{3}$-type monomer and their photoinduced radical polymerization. It was then found that the reactivity of the photo-induced radical polymerization of HBPs was higher than that of the linear one. Furthermore, it was evident that cured films of HBPs exhibited a low birefringence.

Nishikubo and Ozaki ${ }^{17}$ reported the synthesis of polyesters by the polycondensation of bisalkylhalide with dicarboxylic acid using 1,8diazabicyclo[5.4.0] undec-7-ene (DBU) as a base. This reaction is simple and convenient for the synthesis of polyesters because preparation of the activated dicarboxylic acid is not necessary and polycondensation proceeds under mild conditions.

Given this background, we examined the synthesis of a HBPE by the reaction of 1,4-bis(chloromethyl)benzene (BCMB) with 1,3,5-benzenetricarboxylic acid (BTCA) using DBU as a base. We also performed the synthesis and photo-induced radical polymerization of a HBPE containing methacryloyl groups. 


\section{EXPERIMENTAL PROCEDURE}

Materials

Dimethylformamide, dimethylacetamide, $N$-methylpyrrolidone and dimethyl sulfoxide (DMSO) were dried with $\mathrm{CaH}_{2}$ and purified by distillation before use. Chlorobenzene, $o$-dichlorobenzene, methacrylic acid and DBU (donated from San-Apro Ltd., Tokyo, Japan) were purified by distillation in vacuo. BTCA and 2-methyl-1-[4-(methylthio)phenyl]-2-morpholinopropan-2-one (Irgacure 907, Ciba Japan KK, Hyogo, Japan) were used without further purification. BCMB was purified by recrystallization from appropriate solvents.

\section{Measurements}

Infrared (IR) absorption spectra were measured on a THERMO-ELECTRON Nicolet380 (Thermo Electron, Kyoyo, Japan). The ${ }^{1} \mathrm{H}$ nuclear magnetic resonance (NMR) spectrum was recorded on a JEOL (Tokyo, Japan) JNM $\alpha-500$ $\left(500 \mathrm{MHz}\right.$ for $\left.{ }^{1} \mathrm{H} \mathrm{NMR}\right)$ in DMSO- $d_{6}$. The number-average molecular weights $\left(M_{\mathrm{n}}\right)$ and molecular weight distributions $\left(M_{\mathrm{w}} / M_{\mathrm{n}}\right)$ of the polymers were estimated by size exclusion chromatography (SEC) using a TOSOH (Tokyo, Japan) HLC-8220 SEC equipped with refractive index and UV detectors using TSK gel columns (eluent: solution of $\mathrm{LiBr}$ and phosphoric acid $(20 \mathrm{~mm})$ in dimethylformamide) calibrated with narrow-molecular-weight polystyrene standards. Real-time IR absorption spectra were recorded on a BIO-RAD (Tokyo, Japan) Excalibur FTS-3000MX spectrometer equipped with a HOYA-SCHOTT EX250 UV light source (HOYA, Tokyo, Japan).

Synthesis of HBPE by polycondensation of BCMB with BTCA A typical procedure for the polycondensation of $\mathrm{BCMB}$ with $\mathrm{BTCA}$ is as follows. The mixture of BCMB $(0.266 \mathrm{~g} ; 1.5 \mathrm{mmol})$, BTCA $(0.210 \mathrm{~g} ; 1.0 \mathrm{mmol})$ and DBU $(0.457 \mathrm{~g} ; 3.0 \mathrm{mmol})$ in DMSO $(1.25 \mathrm{ml})$ was stirred for $60 \mathrm{~min}$ at $30^{\circ} \mathrm{C}$. The resulting mixture was poured into a large amount of $1 \mathrm{~N}$ hydrochloric acid to precipitate the polymer. The resulting polymer was reprecipitated twice from tetrahydrofuran (THF) into hexane and dried in vacuo at room temperature for $24 \mathrm{~h}$. The yield of the HBPE was $0.323 \mathrm{~g}(68 \%)$. The $M_{\mathrm{n}}$ of the HBPE, estimated by SEC, was $3300\left(M_{\mathrm{w}} / M_{\mathrm{n}}=3.9\right)$. IR (film, $\left.\mathrm{cm}^{-1}\right)$ : 1721 ( $v_{\mathrm{C}=\mathrm{O}}$ of ester). ${ }^{1} \mathrm{H}$ NMR (500 MHz, DMSO- $d_{6}$, $\delta$, p.p.m.): $4.50-4.91\left(\mathrm{~m}, 0.50 \mathrm{H},-\mathrm{CH}_{2}-\mathrm{Cl}\right), 5.03-5.50$ $\left(\mathrm{m}, 5.68 \mathrm{H},-\mathrm{CH}_{2}-\mathrm{O}-\right), 7.00-7.93(\mathrm{~m}, 6.18 \mathrm{H}$, aromatic $\mathrm{H}), 8.10-8.92(\mathrm{~m}, 3.0 \mathrm{H}$, aromatic $\mathrm{H})$ and $12.00-15.00(\mathrm{br}, \mathrm{COO} \underline{\mathrm{H}})$.

\section{Synthesis of HBPE containing methacryloyl groups (HBPE-MA)}

The mixture of HBPE $\left(0.200 \mathrm{~g}, M_{\mathrm{n}}=3300, M_{\mathrm{w}} / M_{\mathrm{n}}=3.9\right)$, MA $(0.172 \mathrm{~g}$, $2.0 \mathrm{mmol})$ and DBU $(0.304 \mathrm{~g}, 2.0 \mathrm{mmol})$ in DMSO $(2.0 \mathrm{ml})$ was stirred for $6 \mathrm{~h}$ at $60^{\circ} \mathrm{C}$. The resulting mixture was poured into a large amount of $1 \mathrm{~N}$ hydrochloric acid to precipitate the polymer. The resulting polymer was reprecipitated twice from THF into hexane and dried in vacuo at room temperature for $24 \mathrm{~h}$. The yield of the HBPE-MA was $0.340 \mathrm{~g}$. The $M_{\mathrm{n}}$ of the HBPE-MA, estimated by SEC, was $3300\left(M_{\mathrm{w}} / M_{\mathrm{n}}=4.0\right)$. IR (film, $\left.\mathrm{cm}^{-1}\right): 1721$ $\left(v_{\mathrm{C}=\mathrm{O}}\right.$ of ester), $1636\left(v_{\mathrm{C}=\mathrm{C}}\right.$ methacryl). ${ }^{1} \mathrm{H}$ NMR $\left(500 \mathrm{MHz}, \mathrm{DMSO}-d_{6}, \delta\right.$, p.p.m.): $1.70-1.90$ (m, 0.6 H, $\left.\mathrm{C}\left(\mathrm{CH}_{3}\right)=\mathrm{CH}_{2}\right), 4.50-5.50$ (m, $6.0 \mathrm{H},-\mathrm{CH}_{2}-\mathrm{O}-$ ), 5.50-6.30 $\left(\mathrm{m}, 0.8 \mathrm{H}, \mathrm{C}\left(\mathrm{CH}_{3}\right)=\mathrm{CH}_{2}\right), 9.89-7.63(\mathrm{~m}, 6.0 \mathrm{H}$, aromatic $\overline{\mathrm{H}})$ and $8.05-8.90(\mathrm{~m}, 3.0 \mathrm{H}$, aromatic $\mathrm{H})$.

\section{Photo-induced radical polymerization}

The photo-induced radical polymerization of HBPE-MA as a solid film was performed as follows. HBPE-MA (97 wt\%) and Irgacure907 (3 wt\%), which was used as a photo-initiator, were dissolved in THF and dried to make a film on a $\mathrm{KBr}$ plate. The film, containing the photo-initiator, was irradiated with a 250-W high-pressure mercury lamp (HOYA-SCHOTT) without a filter in air. The intensity of the light was kept at $8 \mathrm{~mW} \mathrm{~cm}^{-2}$ (at $254 \mathrm{~nm}$ ). The rate of decrease in the $\mathrm{C}=\mathrm{C}$ stretching, near $1636 \mathrm{~cm}^{-1}$, due to the methacryloyl group in HBPE-MA was measured by real-time IR.

\section{RESULTS AND DISCUSSION}

\section{Synthesis of HBPE}

We examined the effect of time on the polycondensation of BCMB with BTCA at $30^{\circ} \mathrm{C}$ in DMSO using DBU as a base (Scheme 1). As summarized in Table 1, the yield of the part of the resulting polymers that were soluble in THF increased with time, up to $60 \mathrm{~min}$. However, at $70 \mathrm{~min}$, parts insoluble in THF (gel products) appeared and the gel product increased with time. This indicates that $60 \mathrm{~min}$ is a suitable reaction time to obtain only a soluble polymer under the specific reaction condition.

The structure of the resulting polyester, by the reaction at the 60-min mark (at which $M_{\mathrm{n}}=3300$ and $M_{\mathrm{w}} / M_{\mathrm{n}}=3.9$ ), was confirmed

Table 1 Effect of reaction time on the polycondensation of $\mathrm{BCMB}$ with BTCA

\begin{tabular}{lrrrr}
\hline Run & Reaction time (min) & Yield (\%) & $\mathrm{M}_{n}^{\mathrm{b}, \mathrm{c}}$ & $\mathrm{M}_{w} / \mathrm{M}_{n}^{\mathrm{b}, \mathrm{c}}$ \\
\hline 1 & 5 & $22^{\mathrm{b}}$ & 750 & 1.2 \\
2 & 10 & $51^{\mathrm{b}}$ & 800 & 1.5 \\
3 & 30 & $60^{\mathrm{b}}$ & 2200 & 3.2 \\
4 & 60 & $68^{\mathrm{b}}$ & 3300 & 3.9 \\
5 & 70 & $60(4)^{\mathrm{b}, \mathrm{d}}$ & 1500 & 3.4 \\
6 & 90 & $43(22)^{\mathrm{b}, \mathrm{d}}$ & 1500 & 4.9 \\
\hline
\end{tabular}

Abbreviations: BCMB, 1,4-bis(chloromethyl)benzene; BTCA, 1,3,5-benzenetricarboxylic acid The reaction was carried out with $\mathrm{BCMB}(1.5 \mathrm{mmol})$ and $\mathrm{BTCA}(1.0 \mathrm{mmol})$ using 1,8 diazabicyclo[5.4.0]undec-7-ene $(3.0 \mathrm{mmol})$ in dimethyl sulfoxide $(1.25 \mathrm{ml})$ at $30^{\circ} \mathrm{C}$ for various times.

boluble parts in tetrahydrofuran (THF)

'Estimated by size exclusion chromatography based on polystyrene standards. Insoluble parts in THF.<smiles></smiles><smiles>CC(C)(C)Cc1ccc(COC(=O)c2cc(C(=O)OC(C)(C)C)cc(C(=O)OC(C)(C)C)c2)cc1</smiles>

Scheme 1 Synthesis of HBPE. 

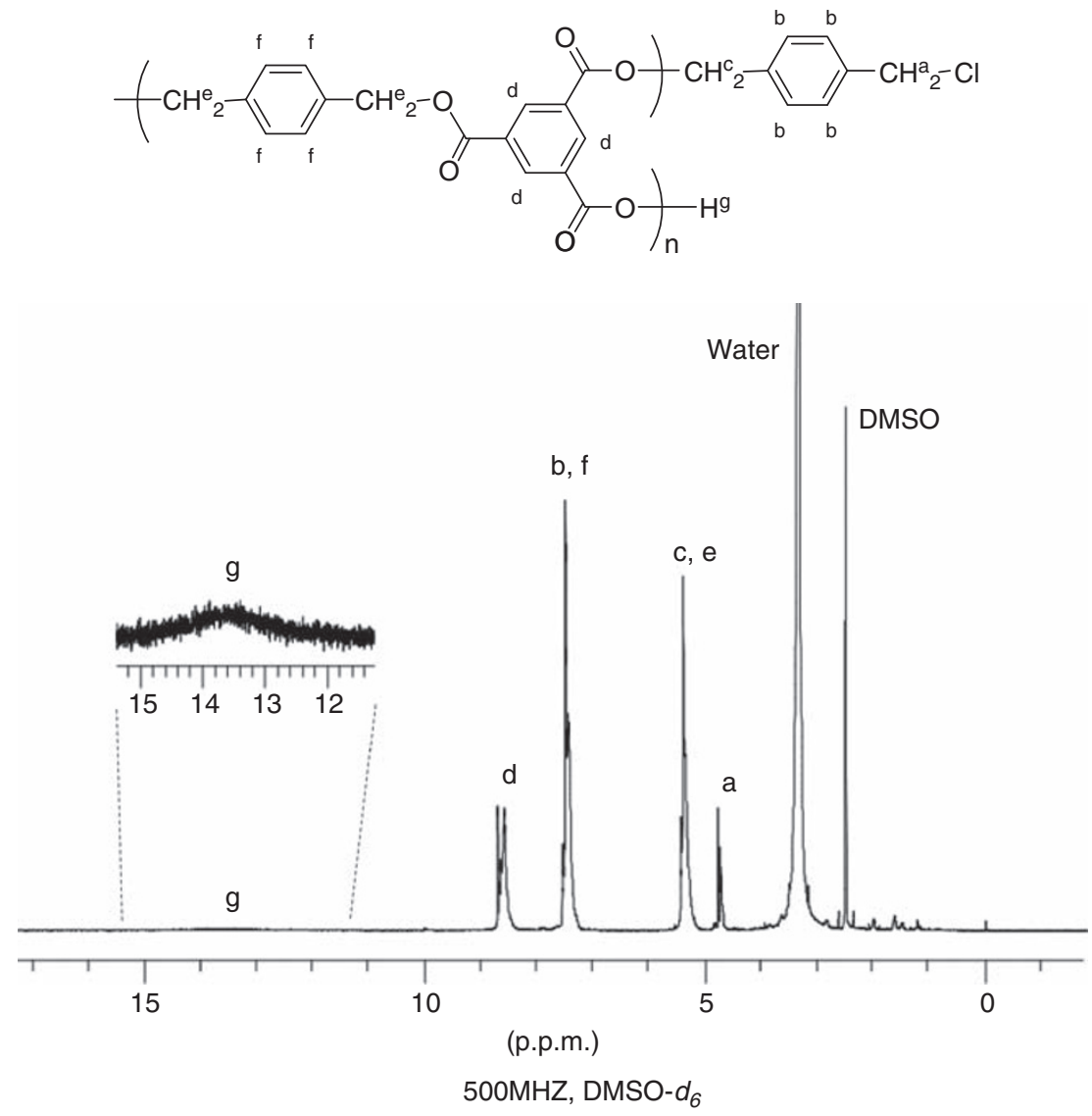

Figure $1^{1} \mathrm{H}$ NMR spectrum of hyperbranched polyester.

Table 2 Effect of solvent on the polycondensation of BCMB with BTCA $^{a}$

\begin{tabular}{llccc}
\hline Run & Solvent & Yield (\%) & $M_{n}^{\mathrm{b}, \mathrm{c}}$ & $M_{w} / M_{n}^{\mathrm{b}, \mathrm{c}}$ \\
\hline 1 & Chlorobenzene & 0 & - & - \\
2 & o-Dichlorobenzene & 0 & - & - \\
3 & DMF & 56 & 1100 & 1.5 \\
4 & DMAc & 61 & 1200 & 1.5 \\
5 & NMP & 60 & 1200 & 1.6 \\
6 & DMSO & 68 & 3300 & 3.9 \\
\hline
\end{tabular}

Abbreviations: BCMB, 1,4-bis(chloromethyl)benzene; BTCA, 1,3,5-benzenetricarboxylic acid aThe reaction was carried out with BCMB $(1.5 \mathrm{mmol})$ and BTCA $(1.0 \mathrm{mmol})$ using 1 , 8 -

diazabicyclo[5.4.0]undec-7-ene $(3.0 \mathrm{mmol})$ in various solvents $(1.25 \mathrm{ml})$ at $30^{\circ} \mathrm{C}$ for $60 \mathrm{~min}$.

bSoluble parts in THF.

'Estimated by size exclusion chromatography based on polystyrene standards.

by IR and ${ }^{1} \mathrm{H}$ NMR spectroscopies. The IR spectrum showed characteristic absorption peaks at $1721 \mathrm{~cm}^{-1}$, assignable to the $\mathrm{C}=\mathrm{O}$ (ester). As shown in Figure 1, the ${ }^{1} \mathrm{H}$ NMR spectrum of this polymer showed proton signals due to chloromethyl groups $\left(\mathrm{H}^{\mathrm{a}}\right)$ at the ends of the polymer chains at $4.50-4.91$ p.p.m. and due to carboxyl groups $\left(\mathrm{H}^{\mathrm{g}}\right)$ at the ends of the polymer chains at $12.00-15.00$ p.p.m. This result suggested that an HBPE, with chloromethyl groups and carboxyl groups at the ends of the polymer chains, was prepared.

The effect of the reaction medium was examined at the $60-\mathrm{min}$ point under the same conditions that yielded the results of Table 1. As summarized in Table 2, the polycondensation of BCMB with BTCA
Table 3 Effect of reaction temperature on the polycondensation of BCMB with BTCA ${ }^{a}$

\begin{tabular}{|c|c|c|c|c|}
\hline Run & Reaction temperature $\left({ }^{\circ} \mathrm{C}\right)$ & Yield (\%) & $\mathrm{M}_{n}^{\mathrm{b}, \mathrm{c}}$ & $\mathrm{M}_{w} / \mathrm{M}_{n}^{\mathrm{b}, \mathrm{c}}$ \\
\hline 1 & 0 & $25^{b}$ & 630 & 1.8 \\
\hline 2 & 30 & $68^{b}$ & 3300 & 3.9 \\
\hline 3 & 60 & $3(71)^{b, d}$ & - & - \\
\hline 4 & 80 & $1(75)^{b, d}$ & - & - \\
\hline \multicolumn{5}{|c|}{$\begin{array}{l}\text { Abbreviations: BCMB, 1,4-bis(chloromethyl)benzene; BTCA, 1,3,5-benzenetricarboxylic acid. } \\
\text { aThe reaction was carried out with BCMB }(1.5 \mathrm{mmol}) \text { and BTCA }(1.0 \mathrm{mmol}) \text { using } 1,8- \\
\text { diazabicyclo[5.4.0]undec-7-ene }(3.0 \mathrm{mmol}) \text { in dimethyl sulfoxide }(1.25 \mathrm{ml}) \text { at various } \\
\text { temperatures for } 60 \mathrm{~min} \text {. } \\
\text { bSoluble parts in THF. } \\
\text { cEstimated by size exclusion chromatography based on polystyrene standards. } \\
\text { dInsoluble parts in THF. }\end{array}$} \\
\hline
\end{tabular}

proceeded in dimethylformamide, dimethylacetamide, $N$-methylpyrrolidone and DMSO to give the soluble polymers. HBPE with the highest molecular weight was obtained when using DMSO as a solvent. No reactions occurred in chlorobenzene or in $o$-dichlorobenzene because BTCA was insoluble in these solvents under the specific reaction condition.

This means that DMSO is a suitable reaction solvent for the polycondensation of BCMB with BTCA to yield an HBPE.

We also examined the effect of reaction temperature while using DBU as a base in DMSO. As shown in Table 3, the yield of the part of HBPE soluble in THF, as well as the $M_{\mathrm{n}}$ values, increased with temperatures ranging from 0 to $30^{\circ} \mathrm{C}$. However, when the poly- 
condensations were performed at 60 and $80{ }^{\circ} \mathrm{C}$ for $60 \mathrm{~min}, 92$ and $97 \%$ of gel products was obtained, respectively. Therefore, it seems that $30{ }^{\circ} \mathrm{C}$ is a suitable reaction temperature to obtain soluble HBPs in good yields.

Table 4 Effect of feed ratio of BTCA on the polycondensation of BCMB with BTCA ${ }^{\mathrm{a}}$

\begin{tabular}{lccccc} 
Run & $\begin{array}{c}\text { Feed ratio (mmol) } \\
\text { BCMB/BTCA }\end{array}$ & Yield $(\%)^{\mathrm{b}}$ & $\mathrm{M}_{n}^{\mathrm{b}, \mathrm{c}}$ & $\mathrm{M}_{w} / \mathrm{M}_{n}^{\mathrm{b}, \mathrm{c}}$ & $\mathrm{COOH}(w t \%)^{\mathrm{d}}$ \\
\hline 1 & $1.5 / 0.8$ & 40 & 800 & 2.0 & 7.41 \\
2 & $1.5 / 0.9$ & 58 & 900 & 2.9 & 7.81 \\
3 & $1.5 / 1.0$ & 68 & 3300 & 3.9 & 8.20 \\
4 & $1.5 / 1.1$ & 63 & 1300 & 2.4 & 8.74 \\
5 & $1.5 / 1.2$ & 54 & 1100 & 2.3 & 9.13 \\
\hline
\end{tabular}

Abbreviations: BCMB, 1,4-bis(chloromethyl)benzene; BTCA, 1,3,5-benzenetricarboxylic acid. The reaction was carried out with $\mathrm{BCMB}(1.5 \mathrm{mmol})$ and $\mathrm{BTCA}(1.0 \mathrm{mmol})$ using 1,8 diazabicyclo[5.4.0]undec-7-ene $(3.0 \mathrm{mmol})$ in dimethyl sulfoxide $(1.25 \mathrm{ml})$ at $30^{\circ} \mathrm{C}$ for $60 \mathrm{~min}$. boluble parts in THF.

CEstimated by size exclusion chromatography based on polystyrene standards.

dEstimated by titration of carboxyl groups in polymer. ${ }^{18}$
The effect of the feed ratio of BTCA was also examined at $30^{\circ} \mathrm{C}$ for 60 min in DMSO using DBU as the base. As summarized in Table 4, an HBPE with the highest molecular weight was obtained when the feed ratio of BCMB:BTCA was 1.5:1. It was also found that the molecular weights decreased with a decreasing and increasing feed ratio of BTCA. It is also suggested that carboxyl group contents increased with increasing feed ratio of BTCA under the specific reaction condition.

\section{Synthesis of HBPE-MA}

The introduction of methacryloyl groups into HBPE was performed (Scheme 2). The reaction of HBPE $\left(M_{\mathrm{n}}=3300, M_{\mathrm{w}} / M_{\mathrm{n}}=3.9\right)$ with methacrylic acid was performed while using DBU as a base, at $60^{\circ} \mathrm{C}$, for $6 \mathrm{~h}$. The corresponding hyperbranched ester containing $>99 \%$ of the pendant methacryloyl groups (HBPE-MA) was obtained. The degree of conversion of the chloromethyl groups was $>99 \%$, which was confirmed by ${ }^{1} \mathrm{H}$ NMR spectroscopy.

The structure of HBPE-MA was confirmed by ${ }^{1} \mathrm{H}$ NMR and IR spectroscopy. The IR spectrum showed characteristic absorption peaks<smiles>CC(C)(C)Cc1ccc(COC(=O)c2cc(C(=O)OC(C)(C)C)cc(C(=O)OC(C)(C)c3ccccc3)c2)cc1</smiles><smiles>C=C(C)C(=O)O</smiles>

HBPE

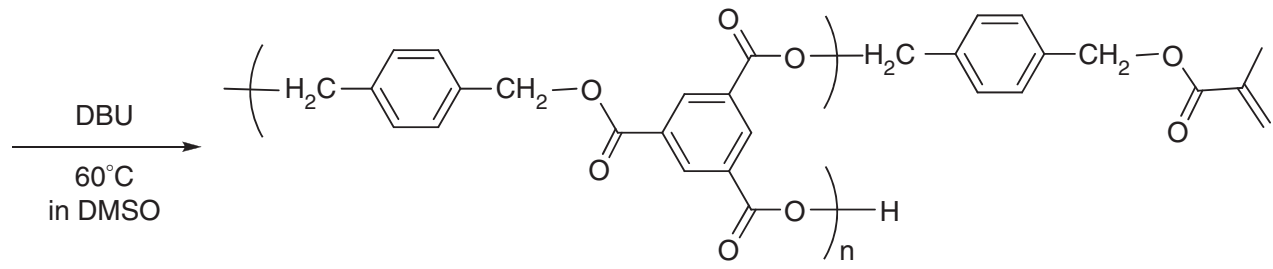

HBPE-MA

Scheme 2 Synthesis of HBPE-MA.
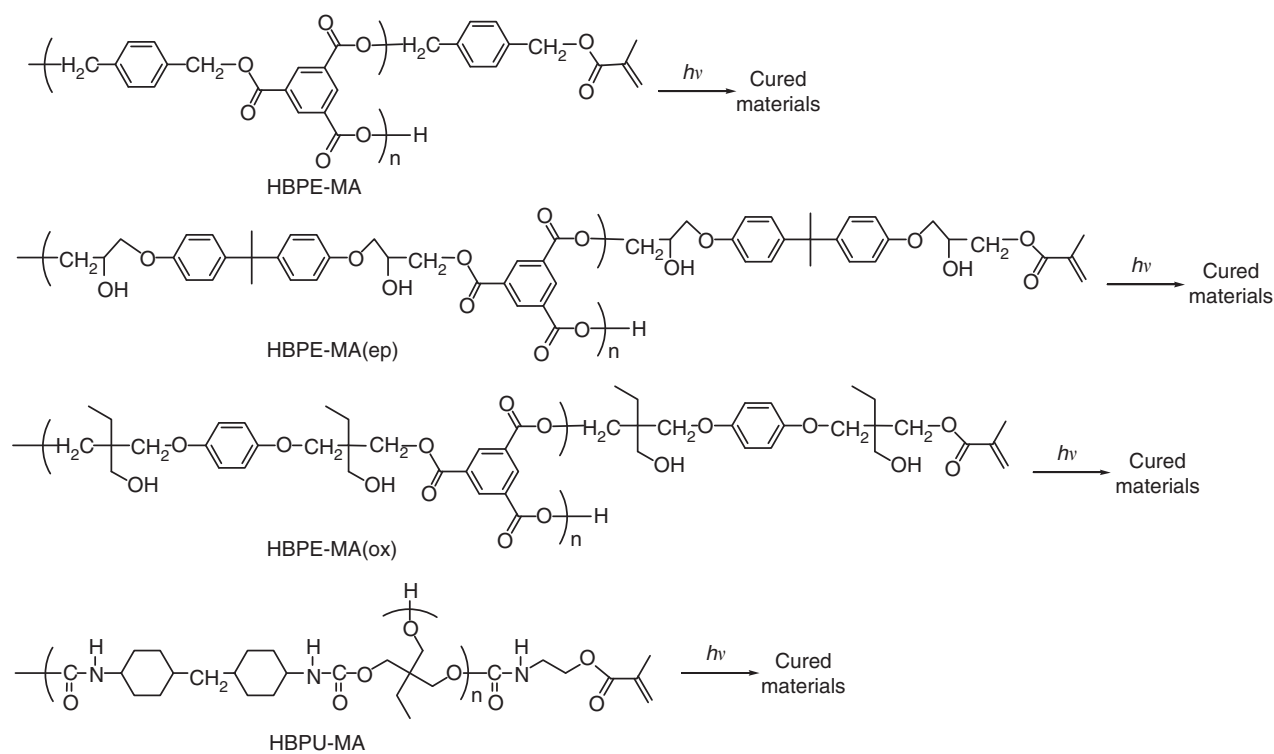

Scheme 3 Photo-initiated radical polymerization. 




Figure 2 Time-conversion curve of the photo-induced radical polymerizations: [A] HBPE-MA (97wt\%) and photo-initiator (3wt\%), [B] HBPE(ep)MA (97wt\%) and photo-initiator (3wt\%), [C] HBPE(ox)-MA (97wt\%) and photo-initiator (3wt\%), and [D] HBPU-MA (97wt\%) and photo-initiator (3wt\%).

at 1721 and $1636 \mathrm{~cm}^{-1}$, which are assignable to the $\mathrm{C}=\mathrm{O}$ and $\mathrm{C}=\mathrm{C}$ (methacryloyl), respectively. The ${ }^{1} \mathrm{H}$ NMR spectrum of this polymer showed proton signals due to methacryloyl groups at 5.50-6.30 p.p.m. Furthermore, characteristic proton signals due to chloromethyl groups at $4.50-4.91$ p.p.m. were not observed. This result means that HBPE with methacryloyl groups was prepared. The HBPE(ep)MA $\left(M_{\mathrm{n}}=5900,98 \%\right.$ epoxy group degree of conversion), HBPE(ox)MA $\left(M_{\mathrm{n}}=3600,54 \%\right.$ oxetanyl group degree of conversion $)$ and HBPU-MA $\left(M_{\mathrm{n}}=2900,67 \%\right.$ hydroxyl group degree of conversion) (Scheme 3) were also prepared, as reported, as references for comparison with HBPE. ${ }^{14-16}$

\section{Photo-initiated radical polymerization of HBPE-MA}

The photo-initiated radical polymerizations of HBPE-MA, HBPE(ep)MA, HBPE(ox)-MA and HBPU-MA were performed in a solid film state, which was prepared with Irgacure 907 (3 wt\%) acting as a photoinitiator under UV irradiation. A 250-W high-pressure mercury lamp (intensity: $8.0 \mathrm{~mW} \mathrm{~cm}^{-2}$ at $254 \mathrm{~nm}$ ) (Scheme 3) was used as the UV source. The conversion rate of the methacryloyl groups was calculated from the decrease of the absorbance at $1636 \mathrm{~cm}^{-1}$, which is due to the $\mathrm{C}=\mathrm{C}$ (methacryloyl) bond in the solid film state, in the real-time FT-IR spectra. Figure 2 illustrates the relationship between the conversion rate of the radical polymerization and reaction time. The reaction proceeded smoothly and the conversion of HBPE-MA, HBPE(ep)-MA, HBPE(ox)-MA and HBPU-MA reached 96, 58, 86 and $81 \%$, respectively, after $15 \mathrm{~min}$. HBPE-MA showed higher photochemical reactivity than HBPE(ep)-MA, HBPE(ox)-MA and HBPUMA. This result indicated that the mobility of the polymer chains of
HBPE(ep)-MA, HBPE(ox)-MA and HBPU-MA was lower than that of HBPE-MA due to the many pendant hydroxyl groups or urethane linkage in the polymer chains.

\section{CONCLUSION}

From these results, the following conclusions can be drawn: (1) HBPE was synthesized through the polyaddition of BCMB with BTCA using DBU as a base. (2) HBPE-MA was synthesized through the reaction of HBPE with MA. (3) The obtained HBPE-MA showed a high photochemical reactivity.

\section{CONFLICT OF INTEREST}

The authors declare no conflict of interest.

1 Nishikubo, T. (eds). Synthesis and Application of Photosensitive Polymers, (CMC, Tokyo, 1979).

2 Tabata, Y., Takimoto, Y., Tominaga, Y., Nakamoto, H. \& Nishikubo, T. (eds). Ultra-Violet and Electron Beam Curable Materials (CMC, Tokyo, 1989).

3 Tabata, Y., Isobe, T., Otaka, T., Sato, M., Takayama, M., Tominaga, Y. \& Nishikubo, T. (eds). Technology \& Application of UV/EB Curing (CMC, Tokyo, 1997).

4 Shirai, M., Maki, K., Okamura, H., Kaneyama, K. \& Itani, T Non-chemically amplified EUV resist based on PHS. J. Photopolym. Sci. Technol. 22, 111-116 (2009).

5 Turner, S. R., Voit, B. I. \& Mourey, T H All-aromatic hyperbranched polyesters with phenol and acetate end groups: synthesis and characterization. Macromolecules 26, 4617-4623 (1993).

6 Turner, S. R., Walter, F., Voit, B. I. \& Mourey, T. H. Hyperbranched aromatic polyesters with carboxylic acid terminal groups. Macromolecules 27, 1611-1616 (1994).

7 Kim, Y. H. \& Webster, O. W. Hyperbranched polyphenylenes. Macromolecules 25, 5561-5572 (1992).

8 Okazaki, M., Washio, I., Shibasaki, Y. \& Ueda, M. Rapid synthesis of polyamide dendrimers from unprotected $A B_{2}$ building blocks. J. Am. Chem. Soc. 125, 81208121 (2003).

9 Spindler, R. \& Fréchet, J. M. J. Synthesis and characterization of hyperbranched polyurethanes prepared from blocked isocyanate monomers by step-growth polymerization. Macromolecules 26, 4809-4813 (1993).

10 Jikei, M. \& Kakimoto, M. Hyperbranched polymers: a promising new class of materials. Prog. Polym. Sci. 26, 1233-1285 (2001).

$11 \mathrm{Hao}$, J., Jikei, M. \& Kakimoto, M. Synthesis and comparison of hyperbranched aromatic polyimides having the same repeating unit by $A B_{2}$ self-polymerization and $A_{2}+B_{3}$ polymerization. Macromolecules 36, 3519-3528 (2003).

12 Makita, S., Kudo, H. \& Nishikubo, T. Synthesis of alkaline-developable, photosensitive hyperbranched polyimides through the reaction of carboxylic acid dianhydrides and trisamines. J. Polym. Sci. Part A. Polym. Chem. 42, 3697-3707 (2004).

13 Kono, S., Sinananwanich, W., Shibasaki, Y., Ando, S. \& Ueda, M. Synthesis of hyperbranched polymer with degree of branching of approximately $100 \%$ by polycondensation of 2-(4-phenoxyphenoxy)fluorenone. Polym. J. 39, 1150-1156 (2007).

14 Maruyama, K., Kudo, H., Ikehara, T., Ito, N. \& Nishikubo, T. Synthesis of photocrosslinkable hyperbranched polyesters and their film properties. J. Polym. Sci. Part A. Polym. Chem. 43, 4642-4653 (2005).

15 Nishikubo, T., Kudo, H., Maruyama, K., Nakagami, T. \& Miyabe, H. Synthesis of photocrosslinkable hyperbranched polyesters with terminal methacryloyl groups by the one-pot polyaddition of bis(oxetane)s with 1,3,5-benzenetricarboxylic acid and methacrylic acid. Polym. J. 38, 447-456 (2006).

16 Maruyama, K., Kudo, H., Ikehara, T., Nishikubo, T., Nishimura, I., Shishido, A. \& Ikeda, T. Synthesis and properties of photo-cross-linkable hyperbranched poly(urethane)s containing both terminal methacryloyl groups and carboxyl groups. Macromolecules 40, 4895-4900 (2007).

17 Nishikubo, T. \& Ozaki, K. Synthesis of polyesters by the reaction of dicarboxylic acids with alkyl dihalides using the DBU method. Polym. J. 22, 1043-1050 (1990).

18 Nishikubo, T., Kudo, H. \& Nakagami, T. Synthesis of hyperbranched poly(ester)s with pendant hydroxy groups by the polyaddition of bis(oxetane)s with 1,3,5-benzenetricarboxylic acid. Polym. J. 38, 145-152 (2006). 